\title{
The dilemma of Architectural internships
}

Smriti Guglani $^{1}$, Pavani Gupta ${ }^{2}$, Abhay Singh Saini ${ }^{3}$, Tanmay Karan ${ }^{4}$, Shruti S. Nagdeve ${ }^{5}$

${ }_{1,2,3,4}$ Students, School of Planning and Architecture, New Delhi, India; ${ }^{5 *}$ Research Scholar, School of Planning and

Architecture, New Delhi, India.

Email: ${ }^{1}$ ar.smritiguglani@gmail.com, ${ }^{2}$ pavanigupta2209@gmail.com, ${ }^{3}$ abhaysn2020@gmail.com, ${ }^{4}$ tanmay_k@nid.edu, s*suti197phd18@spa.ac.in

\section{Keywords}

Professional Practice, Internships,

Expectations, Mentor's Perspective,

Parameters of Importance, Prioritised

Learning, Site Visits.

\section{Article History}

Received on $14^{\text {th }}$ November 2021

Accepted on $17^{\text {th }}$ January 2022

Published on $5^{\text {th }}$ February 2022

Cite this article

Guglani, S., Gupta, P., Saini, A. S., Karan,

T., \& Nagdeve, S. S. (2022). The dilemma of Architectural internships. International Journal of Students' Research in

Technology \& Management, 10(1), 53-66. https://doi.org/10.18510/ijsrtm.2022.1014

Copyright @ Author

Publishing License

This work is licensed under a Creative Commons Attribution-Share Alike 4.0 International License

\section{INTRODUCTION}

\section{Abstract}

Purpose of the study: Architecture as a field exists in the domains of practicality and precision. Internship is a crucial window that connects the field to the five year course. The research aims to unearth the requirements, expectations, and challenges dictating the internship experience. It also aims to decode the solutions that can help improve and equalize varied experiences.

Methodology: The research draws upon the experiences of the respondents, mentors and the authors as well. The research methods used are surveys and semistructured interviews that have been overlaid onto the literature.

Main Findings: The analysis has been done using qualitative and quantitative techniques to understand the role of interns, mentors, and external factors that have a significant effect on the internship experience. The research analyses the expectations and aspirations of a trainee and the expectations and perspective of the mentor to cohesively understand the disparities and challenges both parties may face. The research, in conclusion, brings out the glaring gaps between the dissemination of architectural design in colleges versus the professional field. The academic disconnect in terms of minimum period of internship needs to be extended for better experiences.

Implications: Aspirant interns must prioritise learning above all else in an internship. Also, firms should encourage interns to do more exploration than just presentation work while colleges should start recognising the importance of interior internships. Hence, the research helps realise the gaps that need to be filled and how internships should be selected carefully as they are important stepping stones into the profession.

Internships in architecture must be wholesome, invigorating as well as rewarding. Internships are the foundation of practical experience and knowledge that an undergraduate enters the profession with. It is that one window in the otherwise boxed up architecture curriculum, that enables a student to experiment with various skills which might eventually lead him on to a path outside of architecture and thus, making the student realize his true calling. A student must select their internship prospects with utmost precision and seriousness. However, students often end up with varied experiences, sometimes unsatisfactory, as they get caught with issues like monetary compensation, deviancies from assigned work, and cross-cultural limitations.

It is important to not undervalue the work architecture interns do, and it undermines their worth. The research throws light on a student and a mentor's expectations and underlying issues both parties face. To further the narrative, the research talks about multi-disciplinary internships - a rapidly growing trend amongst the architectural student fraternity, the trend of International internships, and the disconnect identified from the varied experiences.

As researchers, we must maintain an unbiased perspective and explore all the pros and cons of this research topic, keeping in mind the perspectives of students and architecture firms. The research will be done to understand and state the requirements, duties of stakeholders, problems faced by both sides, and suggested mitigation strategies. The intent is to critically analyze and understand the various nuances and make probable recommendations to the same.

\section{Research Questions}

For this study, there are five major research questions

1. What are the expectations, requirements, and duties on the part of a student regarding architectural internships?

2. What are the issues regarding the ethical duty of trainers regarding passing on the knowledge to the interns? What are the expectations of the mentors?

3. What are the underlying trials and tribulations of doing internships? What challenges and deviancies are faced as an intern? 
4. How do International internships differ from internships in India? What can be learned from them, and what nuances of internships abroad can be side-eyed?

5. Are there any out of the box solutions to cover the gaps regarding internships in India and equalize the varied experiences and expectations?

\section{Objectives}

1. To understand the expectations of students and the requirements of internships.

2. To understand the perspective of a mentor on the current situation of internships.

3. To compare and contrast the procedural and cultural aspects of internships in India and abroad.

4. To find mitigation strategies for addressing the disconnect between academic requirements and professional experience.

\section{Scope}

This research paper limits its scope to Indian students working in Indian firms. However,comparisons and consequent analysis will be undertaken between the situation of Internshipsabroad and in India. The experiences, challenges, and expectations of both students and mentors will be looked at.The scope of this research is also limited to students who have interned within the last five years to analyze the recent trends, expectations, and challenges.

\section{Limitations}

Mentors' interviews are limited, owing to their busy schedule and duration of this research. Due to time constraints and an ongoing Pandemic, on-ground data collection is tough, thus the data collection is limited to online methods. Most of the student respondents are from the School of Planning and Architecture, New Delhi, which might have caused the data to be skewed.

\section{RESEARCH METHODOLOGY}

Since the research topic is experiential and pertains to professional practice in architecture, the research will be carried out based on themes identified regarding overall experience, requirements, and nature of internships. The research will be narrative-based, divided amongst appropriate chapters.

The themes regarding internship experience have been identified based on authors' experience and discussions with the guide. The data has been collected through various sources - participant observation, literature review, guided discussions, surveys, and interviews. To better understand and cover all the nuances of student experiences, a survey was designed and circulated amongst students of architecture who have previously interned. Similarly, to understand the perspective of the mentor, primary interviews were conducted.

The findings of the surveys and interviews have been highlighted and incorporated in the appropriate chapters, to analyze the current situation of internships in India and corroborate and reinforce the theoretical concepts and hypotheses. The primary analysis will be qualitative, and quantitative to deduce conclusions about expectations, challenges, and opportunities the stakeholders face, i.e. mentors and firms.

\section{METHODS OF DATA COLLECTION - SURVEY FOR STUDENTS}

The survey has 19 questions based on the themes of learnings, academic requirements, deviancies, challenges, opportunities, mentorship and stipend during their internship. The survey has 115 respondents, in the 21-25 year age group, belonging to various architecture schools across India. The survey was carried out via online mediums. The list of questions is attached with Appendix 1.

\section{Methods of Data Collection - Interview for Mentors}

The interviews were semi-structured, with questions on expectations of mentors, hiring prospects, challenges faced by them, and the ethical duty. Mentors have been interviewed from the following firms - Architects Design Studio, Gensler Bangalore, Qatar Design Consortium, and SPA Consultancy. The list of questions for the interview are attached in Appendix 2 and interviews are attached in Appendix 3 for reference.

\section{RESEARCH FRAMEWORK}

\section{Summary of sample surveyed - Students}

Below is a summary of the findings based on the questionnaire for students.

Out of the 115 respondents, a maximum of them had interned in India. As per the responses, 50\% ofstudents worked in a small scale firm, $32 \%$ opted for a medium scale firm, and the rest were engaged with an MNC.

The questionnaire included questions on the themes of expectations, challenges, deviancies, mentorship, and stipend the findings of which are covered in the corresponding chapters. 
To summarize the overall pulse of the internship experience, our findings yield that more than half of the respondents feel that only some of their overall expectations were met during the internship.

Most people gave positive feedback on their mentorship, with only $30 \%$ of people ranking their overall internship as below average when asked to mark on a scale of 1-5.

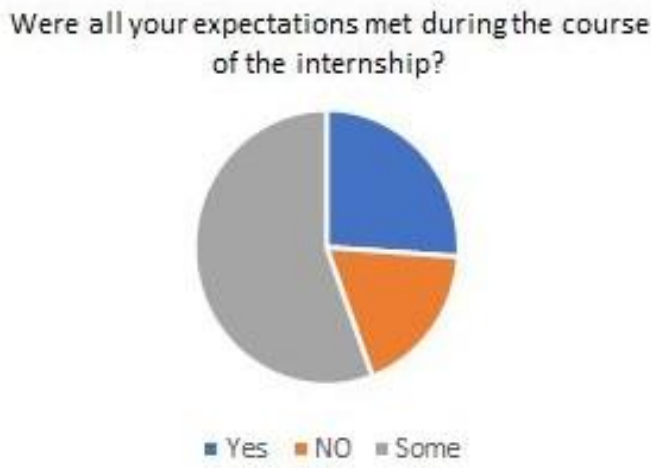

Where did you intern

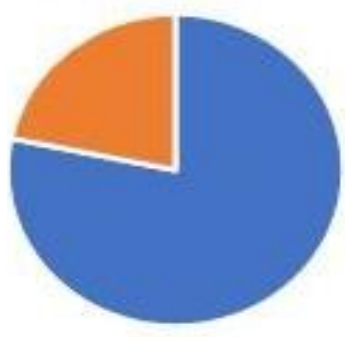

- India = Abroad

\section{Choose the Scale of your firm}

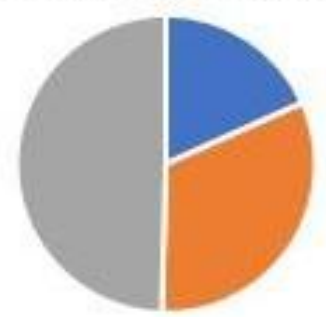

- MNC = Medium Scale = Small Scale

\section{UNDERSTANDING THE NEED FOR INTERNSHIPS}

The internship experience is one of the most anticipated semesters, or year of the five-year architectural program. However, there are certain expectations in the mind of the interns along with the considerations and varied formalities. This chapter will address the context of the basis and need for an architectural internship.

\section{Professional and Academic Requirements}

As an academic requirement, a student enrolled in the graduate program in architecture must undergo one semester of professional training. Architectural colleges in India are under the compliance of COA regulations but have a certain degree of autonomy over the curriculum they administer. All colleges set a minimum requirement for the internship that could vary from a minimum of 12 weeks, like in the case of SPA Delhi to a minimum of 36 weeks, like in the case of Manipal Institute, Mangalore up to the maximum limits of one or two semesters, whichever applicable. The survey findings suggest that maximum colleges stipulate a minimum training period of about 3-4 months. Thus, a student is expected to undergo this minimum training period deemed fit by college, which will add to the students' skill set and prepare them for the real-world situation. However, for an architectural internship, ensuring the most from one in terms of learning, the period must be 24 weeks at least to start with.

One might want to question, why do internships at all? As students, we are always in this protective bubble of academic environments and there is this tendency to steer towards "marks" and being the best student. In this scenario, we might end up ignoring the fact that we are doing a professional course and the knowledge and expertise gained matter the most, as once we graduate and get a license, every line drawn by us could attract liability. Thus, it is imperative to gain firsthand experience as it helps professional development in a multi-faceted way. Furthermore, helps understand the working environment and standard of firms, reveals the hiring prospects, makes us aware of the construction practices and the upcoming trends, and increases our knowledge base and skillset, thus helping in becoming responsible architects of the future.

\section{Expectations of an Internship}

It's important to understand that college teaches us valuable skills but doesn't prepare us for the real professional world.

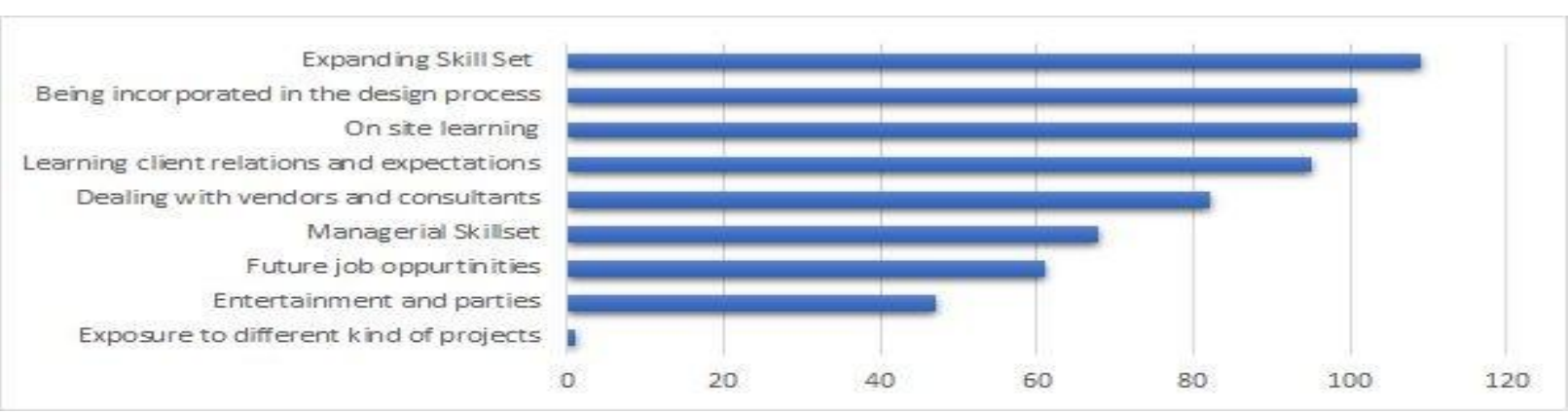

Figure 1: Expectations from the internship [Percentages]

The theoretical knowledge serves as the basis for future development and improvement. It can be overwhelming the first few weeks working as an intern, it can be a rather intimidating experience. Architecture internships can be hectic, exhausting, and stressful sometimes, but should they be like this? A good internship experience would be enjoyable as well as educational. Knowing what to expect from your architecture internship will help you stay on top of things and make your internship an experience you'll never forget. 
The data we gathered from 115 respondents suggests that more than $85 \%$ of the interns expect to improve skills and onsite learning and learn how to act professionally during interaction with clients of which students did not get the chance during academics. $70 \%$ of all respondents also expect to learn to deal with vendors and consultants. $60 \%$ of all interns expect to enhance the managerial skill set as well. Also, more than $50 \%$ wish to explore future job opportunities in the firm. Thus, it gives an insight into what the students are expecting from their internship.

\section{Ethical Considerations on the part of a Student}

As much as the expectations of students vary, students should always have certain ethical considerations on his/her mind. More than $90 \%$ of the respondent interns accept that mentors in various architectural firms expect interns to take responsibility for the work done by them during the internship. Apart from responsibility, mentors expect the trainee to be punctual, professional, and skilled in the software needed in the architectural profession. Interns are expected to communicate with mentors while working on some project given in the office. He/she must be fully committed and aware of the work they do, which means they should not lie about their knowledge base and skill set that might hamper with real-life projects.

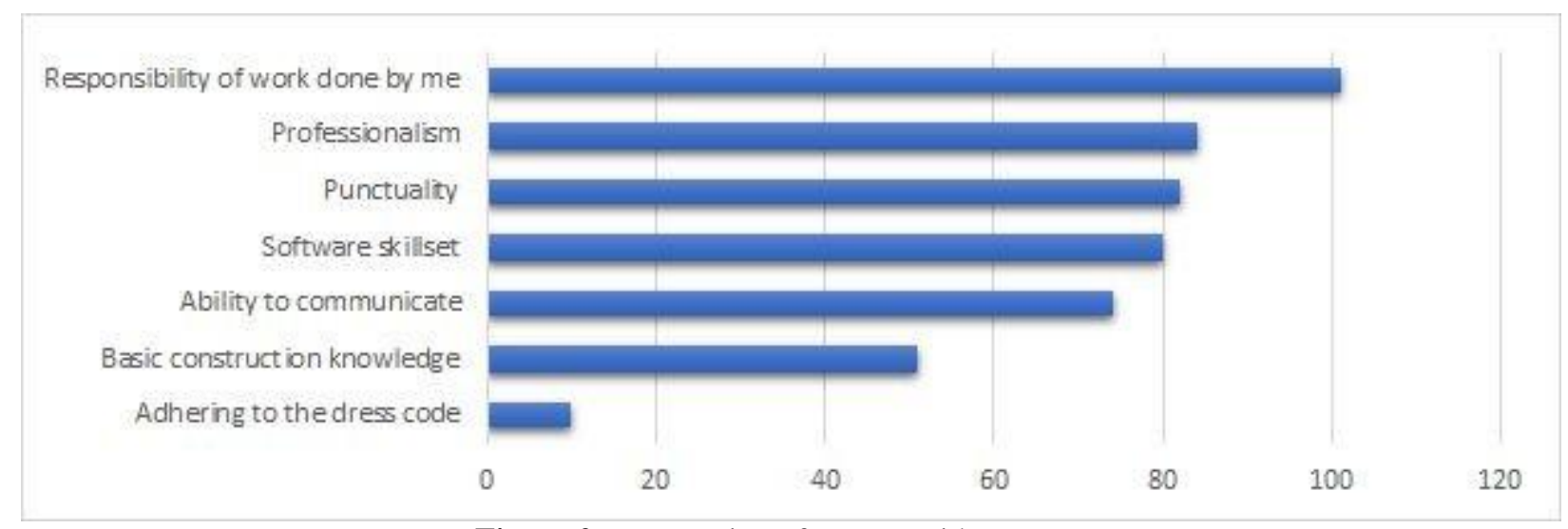

Figure 2: Expectation of mentor with Interns

\section{Application Procedures in India}

To apply for internships in India, students majorly rely on applying via e-mails while in-person interviews are prevalent too. The standard procedure for applying for an internship is to first prepare a portfolio and compile the best academic works. Then the portfolio is published to be sent to firms via mail. Typically most firms have HR emails but some accept applications via their websites. The mail comprises $\mathrm{CV}$, portfolio and a cover letter.

After shortlisting portfolios, the firms set up an interview. In the same cities, the student is expected to give an in-person interview wherein a printed portfolio is also appreciated. Else interviews for cross city internships happen over mediums like phone calls, or skype.

\section{STUDENT PREREQUISITES AND PREPARATION}

This section will focus on how a student should choose the right firm for himself/herself and the various prerequisites for preparing for this journey.

\section{Differentiating between small scale, medium scale, and MNC firms}

When a student is preparing for applications, anticipating replies becomes overwhelming. Due to the expanding availability of interns, and lesser firms with experienced mentors - a student is often left with little choice to be flexible about what firm to work in. But keeping such subjective situations aside, a student must have clarity over the scale and folio of the firm they would want to experience, and prior research is imperative. Following is a broad idea of category of scale of firms:

- Small Scale: At a very minute level, a small scale firm can be just one principal architect and 2 or more interns working under them. Such firms have fewer resources but most work is done with utmost precision. These are a good choice if one wants to learn sitework or specialised architectural design. Example: Spiderglass, Shimla.

- Medium Scale: These are well established city firms, sometimes with 1-2 branches. The portfolio is broader and they have many projects going on at once. These are a good choice when site visits are priority and a quick learning of a project cycle, start to end. For example: Envisage, Incubis, Studio Chintala.

- Large Scale: These firms have global presence with multiple branches. There are various departments, and multiple senior architects. If you want to dig deep in client and consultant relations, real estate management, and interiors, these are a good choice. The scale of the projects is also subsequently large and they allow for exploration for the interns/employees. For Example: Gensler, Morphogenesis, CnT Architects. 
Students must research about the projects undertaken by the firm, the studio life, the mentors and their principles to understand holistically what the firm could offer them. It also helps one understand what to expect from that particular firm. This should carefully be understood to realise if it aligns with the students expectations.

\section{Choosing between specialized verticals and overall exposure}

Another way to choose the right firm to intern is to identify what kind of experience you want in terms of specialisation. For examples, there are firms which specialize in certain design typologies like - masterplan design, healthcare systems, airport, corporate interior or residential interior, and so on. Sometimes students want to learn the design development and process for a certain typology, in which case it makes sense to apply in a firm specialising in that type.

On the other hand, a broader way to go about it is to decide between an architectural design or interior design internship. The survey findings suggest that the ratio of architecture and interior design internships is about 60 versus 40 percent, which suggests that interior design internships are prevalent, or interior work is entrusted to interns. This becomes an important decision because in the five year B.Arch course, interiors is barely paid attention to an internship provides the best opportunity to explore interior design.

\section{Networking Prerequisites}

Networking is perhaps the most important task after research when choosing your internship. Websites are attractive, but online resources could be misleading at times. Also, the interviewer might paint a happy picture but the reality could be far from different.

As per the survey results of the research, $26 \%$ respondents reported having to do work different from what was promised, or what was academically required. But these discrepancies are mostly noticed during the internship experience. This is where networking pitches in to mitigate the risk of ending up in such a work environment. Students can approach the former interns of any firm they are interested in to understand the work culture and overall experience. As the architectural fraternity, we are blessed to have an interlaced network, where most people are approachable over LinkedIn and similar platforms. Apart from this, networking can be effectively utilised to find yourself the right internship and offers in a firm you want. Networking helps a student to be able to communicate and show their interest in a firm as mails can go unnoticed. Thus, networking is a must prerequisite while applying and hunting for internships.

\section{Summary}

Thus, as a concluding note, it is imperative for a student seeking internships, to research systematically, decide on the type of specialization or exposure, and network appropriately to find the right firm and experience for them.

\section{WORK ENVIRONMENT ATTRIBUTES}

This section will address the positive attributes, the learning experience gained, underlying issues and precarities faced by an intern in a work environment and the subsequent implications of these situations.

\section{Learning Experience and Workplace Culture}

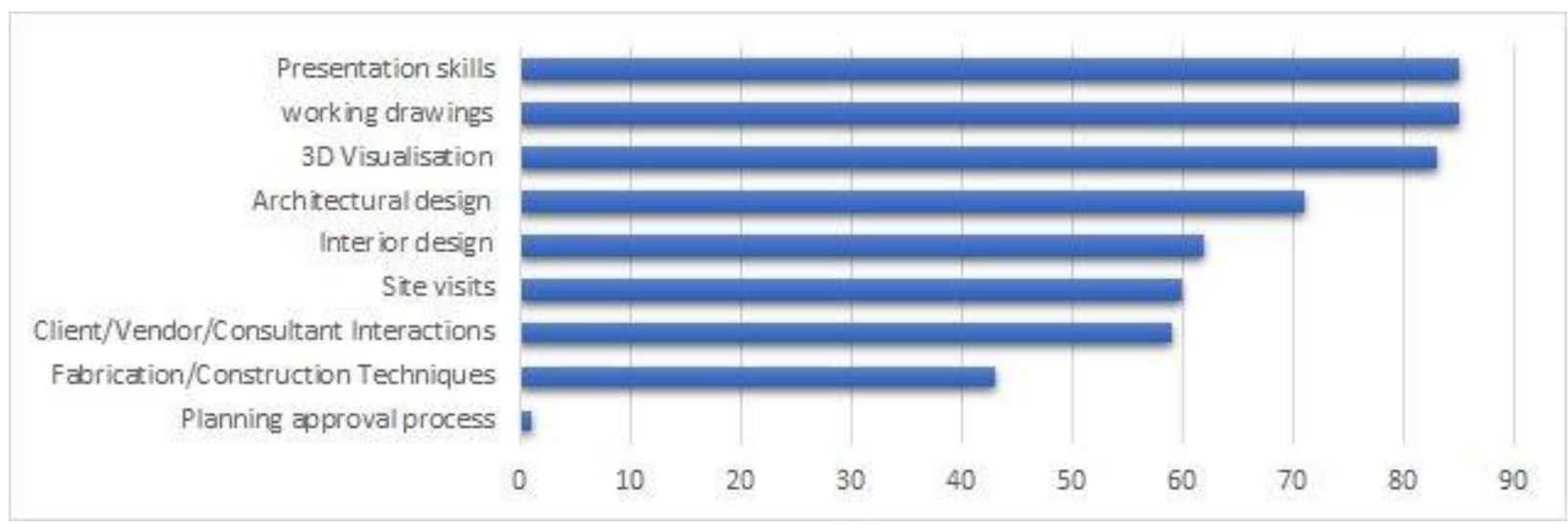

Figure 3: Learning experience acquired in terms of skills

The study has analysed the particular skills that students gain throughout the internship. The above chart reveals that most of the skills honed, and/or acquired were mostly presentation and visualisation skills. Less than a majority of students reported architecture design as a skill they practised.

- Site Visits: These could include continuous involvement in site, such as with construction

- Client Meetings: Vendor interactions mean that interns would learn about joinery details, prices, and availability of materials in market

- Presentation and 3D Visualisation: Getting familiar with softwares, drawing skills etc. 
- Fabrication and Construction: This could be included under site visits

- Architecture Design : Being involved with all the above mentioned, would consequently mean learning architecture design

- Interior Design: Internships are a good way to explore interior design, since architecture programs in colleges may not provide the most detailed outlook.

Analysing the interviews of mentors undertaken for this study, there was a consensus wherein the mentors felt the interns lacked practical knowledge. The gap is formed where just a little over 50 percent of the students were taken to site visits, and a college jury or review requires that students have undergone the same. It is on the accord of the firm to take the intern to site, as much as it is on the student's eagerness. However not all firms have the luxury of time and resources to entrust interns on site, thus students must choose internships after thorough investigation. The fact that mentors feel the absence of practical knowledge amongst interns, corroborates the findings from interns that they were involved mostly with presentation work.

However, keeping apart the skills acquired, the attributes of work culture equally matter as work environments should be healthy, and not toxic. The survey findings yield that most workplaces have positive attributes like constructive criticism, approachability, and balance of work and play. Factors like equal say on the table and informative sessions improve the overall experience. Few students reported to have participated in co-curricular activities and experiencing specialized verticals, which suggests that firms care about their employees beyond just work. Around 66\% of students reported getting involved in some stage of the design process, suggesting that firms trust interns with their responsibility. However, it is not always a bright story as few interns experience deviancies or toxic workplace traits that hamper the wellbeing and learning exposure.

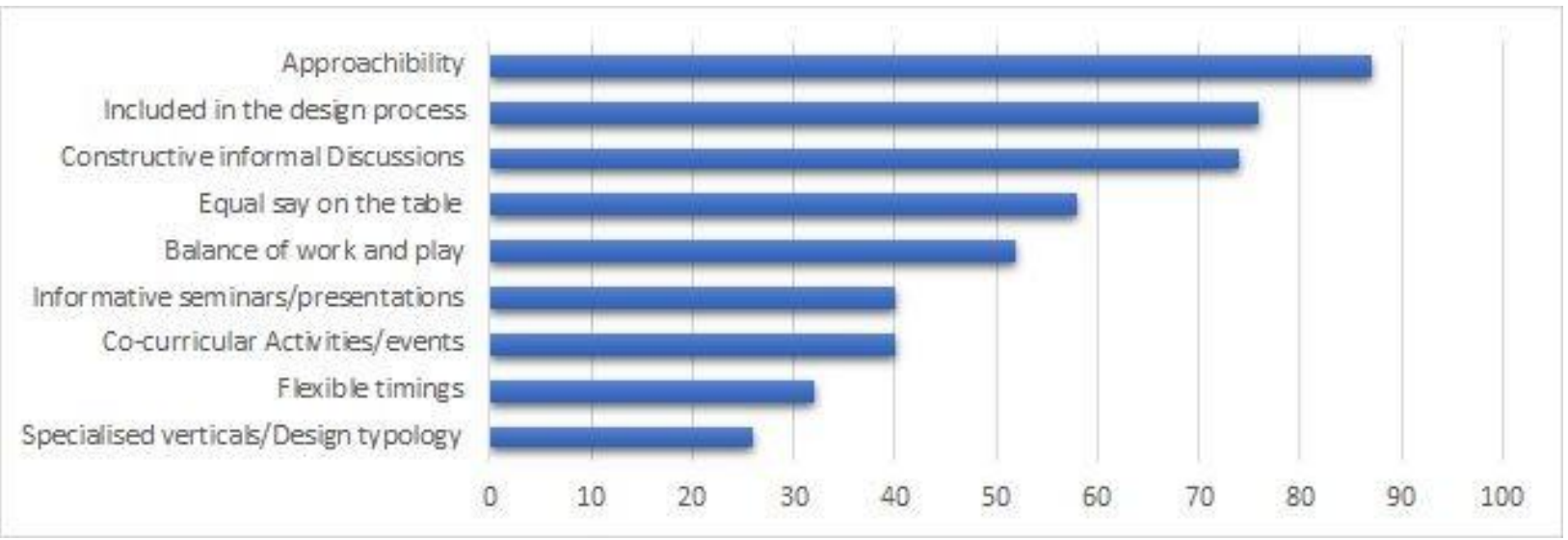

Figure 4: Positive attributes of the work culture at firm (percentages)

\section{Challenges and Deviancies from internship requirements}

The survey was also used to analyze the various types of challenges the interns face in the workplace. Following chart summarizes that the most faced challenges include low/no stipend, longer working hours or a repetitive/ limited scope of work.

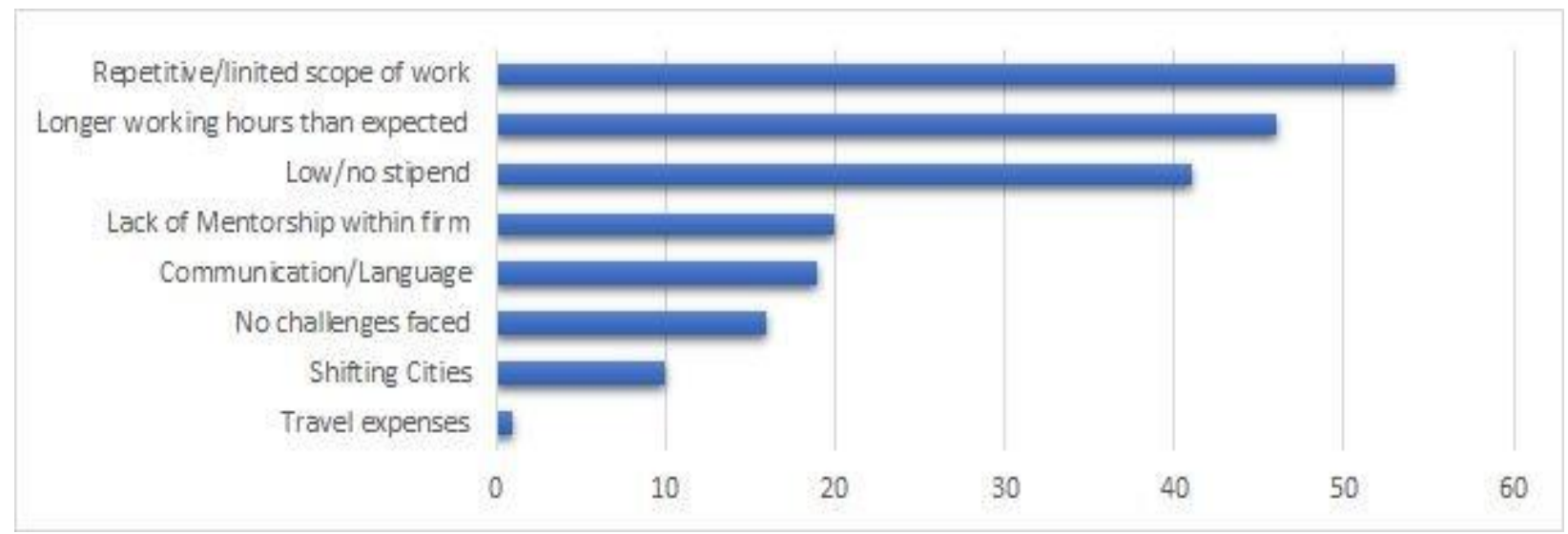

Figure 5: Challenges from the internship [Percentages] 


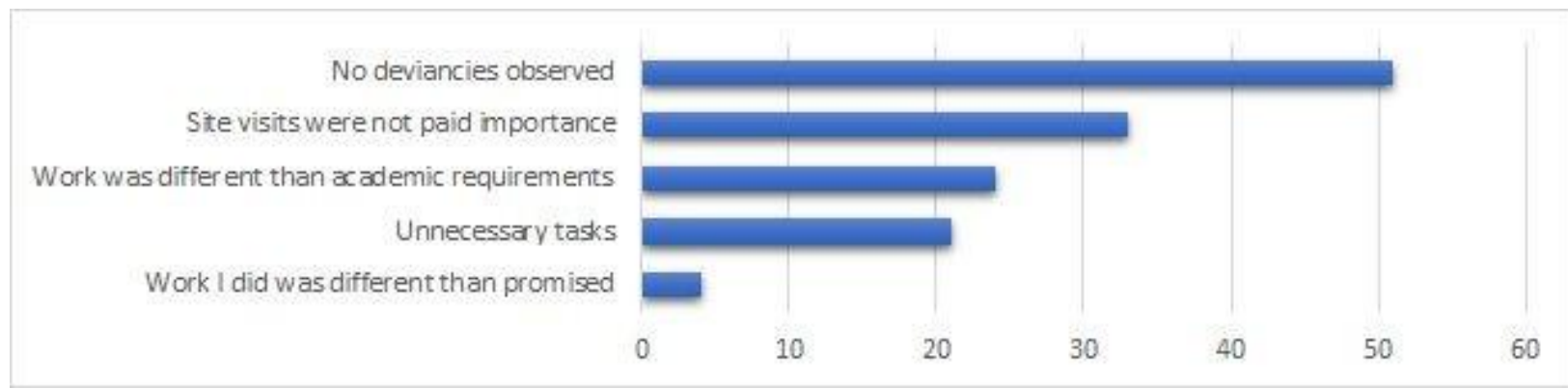

Figure 6: Positive attributes of the work culture at firm (percentages)

There are many issues about students of architecture who are interning, such as less pay, long exhausting hours, working hours beyond stipulated times, wrongful terminations, non architectural work, or work deviant to what the course requires. Often firms and senior architects run out of work and hence they have no work to give to the interns, causing an incomplete experience. Some students may also face issues like not having proper guidance or interaction with senior office members, hence limiting their learnings. (Gündeș, 2017)

Data gathered suggest that about $45 \%$ students did not observe deviancies. Even though most firms try to regulate mentorship programs, the most faced deviancy was that site visits were not paid importance. Unnecessary tasks and work being different from academic requirements are also prevalent. This suggests that interior internships are considered as not "academic", pointing us towards an academic disconnect.

\section{Monetary Issues - Stipend}

Monetary issues are a priority to students from lower-income countries, and groups. Studying architecture isn't inexpensive. Laptops, supplies, and transportation to site visits are expensive, not to mention university college lodging, thus carving holes in students' pockets. In this scenario, students see internships as an opportunity to earn some of that money back.

However stipend should be prioritised least when it comes to learning, internships must emphasize learning over anything else, that would secure better opportunities and work in the future. Similarly, mentors also put in a lot of time and effort, whose time can be equated to money. Thus, learning from a practical and experienced mentor is of prime importance.

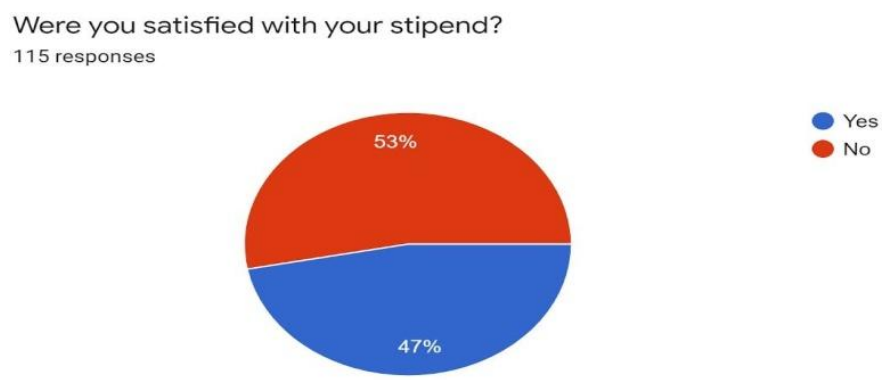

The survey results showed that there was almost a halfway balance between students satisfied with their stipends and those who were not. But in India, more so than any other western nation, there is a disparity among students in terms of monetary income, and architecture as a course is not easy on the pockets. Therefore it is paramount that senior architects and architecture firms reward interns and their work suitably, if not well. However, unfortunately, students blur the line between experience and money, which needs to be made aware of, especially to the upcoming batches.

The survey also inquired about the reason for the low stipend/incomes, which was met with a general consensus that architects are always underpaid. This suggests the underlying issues with the monetary opportunities of the profession itself.

\section{Exploitation - Working hours and Nature of work}

Certain architecture offices like Matthew and Ghosh, Bangalore even demand a fee from students just to be able to intern under them. Even in international terms, the situation is not that good fairing. JunyaIshigami, a reputed firm has been notorious for not paying their interns among other Architects in Japan. Unpaid architecture interns in Japan are exploited by their employers, according to humanitarian architecture pioneer Cameron Sinclair. Karim Rashid, a NYC based designer, who runs an unpaid internship program says that expensive university programs are more exploitative than unpaid internships at a brilliant firm, that could be a career launch for the students.

LAB tokyo founder Nicholas Raistrick stated: "Voluntary work here is quite common and people do make sacrifices without expecting an immediate reward." 
Intern culture "rewards wealthy, privileged designers". "This culture rewards wealthy, privileged designers and pushes out those with economic or social challenges," says Cameron Sinclair, in response. (Unpaid interns are "used and abused' by Japanese architects says Cameron Sinclair,no date)

\section{Cross-Cultural differences arising due to change of cities}

Living and working in a multicultural environment has a lot of enrichment potential, as it promotes awareness and forces us to understand different viewpoints and expertise. This helps stimulate problem solving capabilities and creativity, thus one can better connect with colleagues from different national and cultural contexts.

The prominent challenges faced in a cross-cultural setup are the language barriers andcultural differences. Sometimes there is a personal bias that can unintentionally upset others. Design is the most effective tool in solving social issues and dismantling hierarchy and social disparity. Above all, it's important to remember that it's necessary to understand different cultures and audiences and avoid imposing communication patterns and management patterns that may not suit. This does not mean adapting completely to another cultural context at the

expense of one's goals and priorities. Rather, it is important to work with business partners and clients to negotiate workable communication patterns and routines.

Below are some of the communication strategies that could be attempted when working as an intern in a multicultural setup -

- Do the task immediately and resolve differences when they arise

- Learn about team members by engaging in social activities

- Focus on similarities and group identity while downplaying team-members' differences

- Accept team members that choose to work independently on certain tasks

- Assign team roles according to the national cultural features of each team member

\section{Summary}

It is observed that most students get a fairly decent experience and are usually happy with their exposure but this doesn't mean we ignore the significant percentage of students whoseexperiences are hampered by the underlying issues discussed above. Thus, it is extremely important to educate and be aware of the expectations and situations existing in the profession, to make a good call about one's internship. It is a right of every student to have a fruitful andwholesome internship experience.

\section{MENTOR'S PERSPECTIVE}

\section{Expectations of a mentor}

For a lot of firms where they get a large number of applications, marks and CV become the first criteria for cutoff. Then a clear, concise and diverse portfolio is what the firm judges the intern on. A student's portfolio is the first impression on the employer. Finally through interviews the firms look for interns who are willing to learn at all costs, their attitude and zeal to do new things. Firms need interns who will take an initiative to learn work and ask for it. Some mentors also mentioned that they look for interns with passion for some verticals as the intelligence of the interns cannot be gauged in a half hour interview. Trainers expect interns to have software skills, other than that they don't expect anything from interns in terms of specialised knowledge/skills.

Trainers work with interns as if they're blank slates, as learned from the mentor interviews conducted, because usually interns haven't worked in a professional environment before, and have none to very little knowledge of the workings of architecture. Trainer's ethical duties are patience, willingness to solve doubts and spend ample time with interns under them assigning duties, going over work done through the week, and work to be finished, and work to be assigned, however this will have to happen in sync with the intern and their initiatives to connect with them.

\section{Preparing soon-to-be undergrads for the practical world}

The question here arises, why do firms keep interns at all? This could be answered through multiple perspectives. Hiring interns is considered an ethical responsibility on the part of all practicing architects and paying back to the profession. Some mentors like to train interns purely out of their passion to teach. Interns help in easing out the workload of the firm and can handle basic tasks. Also, they are a good way to identify talent plus keep an eye on the gap between education and practice. Most mentors agree that interns bring a fresh set of ideas, thus helping in the firm's overall development.As per the insights gathered through the interview, each firm has its method of delegating work to the interns. Some mentors believe in focusing on what the interns learn, while others chart out tasks based on availability of projects. Most times, interns are assessed and assignedwork based on their capability. It was observed from the primary analysis that while some firms focus on hiring interns for presentation and drawing work, others do believe in involving interns with ideation and conceptual design. 


\section{Ensuring Quality of Work}

A trainer needs to explain how to do tasks and why those tasks are important. An architectural trainer needs to spend more time with interns than more established workers. It might be unrealistic to give interns a task and expect them to understand it immediately without guidance. The trainer should watch the intern's work closely. They should help as soon as you think they are going in the wrong direction and explain what instead should be done. The trainer should make sure interns learn the right way to do somethingor some project in the office. (Parishani and Khorooshi, 2016). From the data gathered in the student survey, it was observed that 84 percent of the respondents were in direct communication with their mentor or principal architect and could receive guidance from them when needed. The remaining students had other issues such as the mentor being too busy to attend to them. This points to how interns as their primary responsibility must be in sync with their mentors.

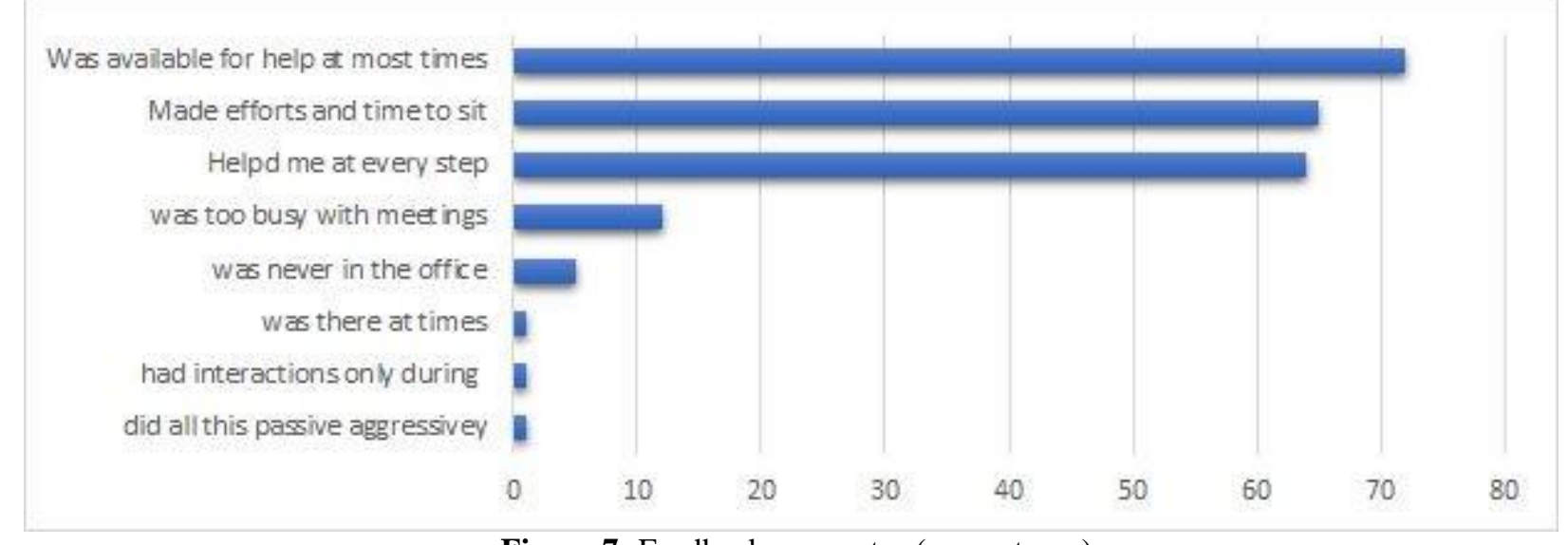

Figure 7: Feedback on mentor (percentages)

\section{Cost to Company and Lack of Knowledge of an Intern}

Firms have to provide lighting, personnel, stipends, and guarantee to train architecture students. Considering these parameters, it becomes exceedingly taxing on firms to get work out of inexperienced interns. However, most mentors believe in providing a minimum decent pay at least, although the final decisions are subject to cash flow and internal specificities.

Firms need resourceful, knowledgeable personnel working for them in order to be efficient. Unfortunately, not every students embarking on internships are prepared to give to the firm as much as the firm is prepared to give to the intern. Lack of knowledge, as an architecture student is combat not easily won, and can prove to be underproductive to the firm and slow down their proceedings. This along with the issues raised by students over unpaid internships can make such programs seem underproductive to firms. As such, many firms have taken up the trend of dropping their internship programs, and internship acceptance altogether. (Elemental endsinternships amid a growing row over unpaid work in architecture studios, 2019b)

Analysis from the mentor interviews reveals that most feel that the students lack basic knowledge of spatial visualization and architectural design. All mentors have a consensus over students having no practical training before working, making the internship even more important. The firms thus stress over a rigorous vetting process for selection of interns. Also observed was, it's not the lack of skills or knowledge, but the lack of understanding on practical translation of theoretical concepts. As one mentor mentioned, students are sometimes hard set in their ideas and notion and must be willing to unlearn and relearn before they step out to work.

\section{Contribution of the intern to the firm}

While it is established that interns are like blank slates, and do not possess enough skills to handle work alone, mentors believe that their willingness to learn makes them an invaluable asset. Mentors also believe that the interns bring a fresh perspective to the table, as they know all the latest trends and softwares. Also, the intern gives back to the firm with their time and respect. The findings yield that mentors believe interns are usually well-versed with renderings and presentation, proving beneficial. As was also corroborated by the findings from the student survey, presentation

work is where interns contribute the most to the firm, and correspondingly, mentors expect that they show initiative and potential to do more than just that.

\section{Future Hiring Prospects}

It was found that firms usually decide the employment of interns based on the following parameters; willingness to learn and work, basic software skills, presence of professional hard and soft skills, academic prowess, etc.

It was observed from the interviews that most of the firms hire their interns as junior architects as it is easier for them to begin with a minimal induction period in the firm because they know the working process of the firm. This way, time is saved, invested by a firm in a junior architect who just joined the firm. 


\section{Summary}

Mentors have a myriad of expectations to be met by interns. It is to be taken as a sort of responsibility to give back to the profession by training potential employees and professionals. Mentors often have to be of assistance to the interns who have no practical knowledge of the workings of an office, but as found from the analysis, mentors do believe that interns havesomething to offer in terms of their fresh perspectives, presentation and software skills.

\section{MULTI-DISCIPLINARY INTERNSHIPS IN ARCHITECTURE}

The beauty of an architecture school is that it gives you the foundation to explore various fields. Internships are a way to do the very same.

\section{Experiential Aspect}

Architecture is a field where it's not only about the site visits and working drawings but consulting, real estate management, graphic design, journalism and other allied fields that are just as important to their parent profession. After doing architecture, many other fields open up and students want to explore new fields related to architecture and the best time for them can be the internship period, so they can see and understand the particular field and decide if they want to pursue it after graduation. This is particularly helpful if someone wants to explore conservation, adaptive reuse, landscape, industrial design, interiors and similar streams.

Several students lose interest in the core architecture work and, so they tend to explore all this in the internship period, but the college does not always necessarily agree with this. For them, it's the time to improve their drawing skills, learn on-site work, etc. and want the students to give them the required type of work. They inherently focus students to gain experience on greenfield projects. So it's important for the college also to encourage the students on multidisciplinary internships and motivate them to explore fields related to architecture to make informed decisions about their future.

\section{Academic Requirement Dilemma}

Many of the staple college requirements, of architecture colleges in India, are site visits and working drawings. Undertaking multidisciplinary internships, in other fields such as photography, product design, art, fashion, may not always be appreciated. Colleges require students to be under an architect's supervision to be working for such allied fields, however, as an academic aspect, it allboils down to juror's perception who will be reviewing work so done.

\section{INTERNATIONAL INTERNSHIPS}

International internships are a great opportunity for exposure, they entail the potential to learn about how architecture is practised in a different geographical location. New people, practices and work cultures can be learnt about, and thus be an asset on a student's CV.

\section{Application Procedure}

It might look very difficult, but getting into such firms is purely merit. The first step is to thoroughly research opportunities and vacancies. Then, one should make sure the portfolio presents them to make them an apt choice for the firm being applied to. For example, if a student wishes to apply to ZHA, their portfolio and skillset must establish how they will be valuable. Applying for the job can be done over websites as well. But an effective way is to network. One can seek help from prior connections or use LinkedIn to seek connections that lead them to talking with people working there. That only helps ramp up the process and makes sure the HR receives an application. Beyond that, it is upto pure merit and confidence.

\section{Work Culture}

About work culture, it is far more structured in many international workspaces. Multinational companies for example foster healthy working environments, there is lesser wage disparity between the genders and human resource is viewed as value addition to the firm. It somewhat also links to the cultural consumption of aesthetics. People in developed countries tend to be progressive and quickly adapt to the changes in culture and technology and thus they understand the importance and relevance of "design" per say. The field of design is given higher value in an international context as it is viewed as a necessity and problem-solving tool rather than an unrequired luxury in an Indian setting. Thus, there is far more job satisfaction and opportunities to satisfy your creative hunger as a designer and an architect.

\section{Difference from Indian Internships}

When you consider going abroad to work for a firm likes BIG or ZHA, it demands that you be extremely efficient and know how to work in and out. These firms get lakhs of applications from across the globe and thus it becomes imperative to establish your niche. One thing to keep in mind is that while applying we compete with all international education systems versus what we have in India. In a way, Indian architectural education is limiting and there is a lack of infrastructure which leads to a sort of redundant form of knowledge, thus students and professionals must bridge this gap in terms of their portfolios and existing knowledge base before deciding to make the move abroad. 


\section{Challenges of International Internships}

A major challenge is obtaining work permits. Most countries have started closing their economies to immigrants to carve more job opportunities for natives. America for example the US H1-B visas have been discouraged for a few years now. Similarly, in Europe, one can easily get a student visa and pursue their studies, but getting a work permit is extremely difficult because it is regulated and charges a hefty amount. Thus, making the move abroad, will most probably cost you more than it pays off initially. Next challenge is the domain of practice. Getting to work in an international firm is quite lucrative, but it directly relates to the context you get educated in. Learning and getting trained in the Indian context, we get accustomed to local practices and design thinking. Making the shift to a diametrically opposite context is very challenging. One would need to unlearn their five years of education and then cast themselves into a context unknown to them. Even though we as architects are trained for such scenarios, understanding the nuances of the culture and people takes some time, maybe years and hence one must consider the amount of hard work they would need to put into the shift.

\section{INTERNSHIP EXPERIENCE}

This chapter focuses on the plurality and polarity of internship experiences - drawing upon some of the common observations from internship accounts. It also discusses how to select an internship experience based on the various parameters identified from the interviews.

\section{Positive Experiences}

Internships are a great way to apply the knowledge a student gets in college to real-world experience. Internships provide students a chance to apply his/her skills in the workforce. An internship provides student experience in the professional field s/he wants to pursue and prepares him/her for what to expect in their field and increase confidence in his/her skills. Having internships benefits the intern to build his/her professional network. The internship provides a great environment to meet professionals who provide their service in the same professional field.

\section{Rate your overall experience of your internship, keeping all the above factors in mind. 115 responses}

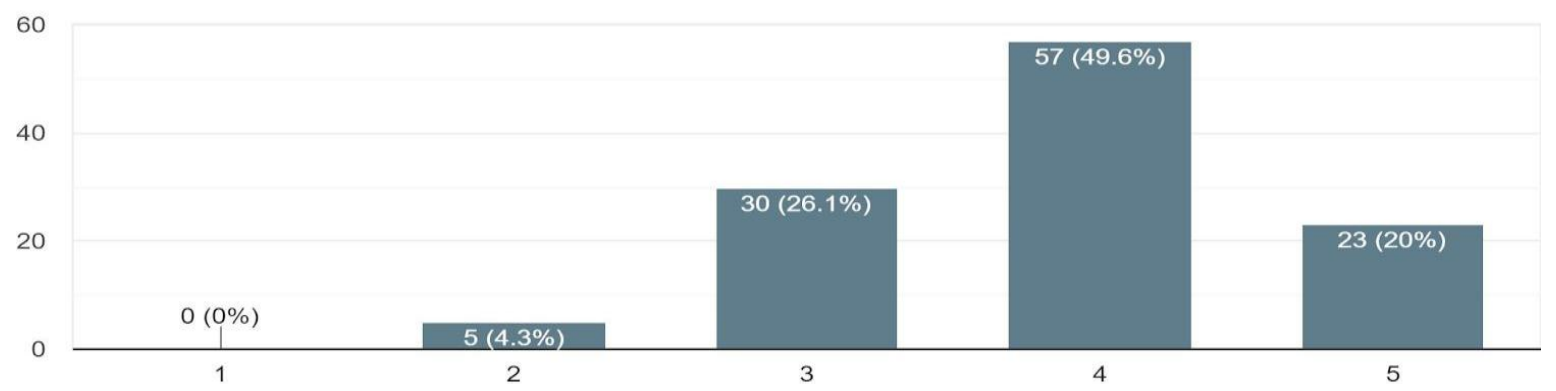

Survey results show, $70 \%$ of the respondents accept that they had a constructive experience in the firm during the internship period and they were provided with an ethical and just environment while working as an intern. The above chart shows the rating the students assigned to the overall experience.

\section{Negative Experiences}

While the survey reveals that most interns feel welcome during their internships, one cannot overlook the negative feedback.. Learning from the negatives is also important because it teaches you how to overcome the challenges, whilst setting your priorities and expectations from the upcoming job experience.

Internships are not supposed to take the fun out of architecture. They should be enjoyable, and wholesome. Some workplace environments are toxic, as they treat interns as cheap labour or visualisers without the students getting any opportunity to learn. There could be other issues such as internal politics, menial tasks, humiliation, and unnecessary overtime. This is why doing preliminary due diligence becomes increasingly important. 


\section{Choosing your Ideal Experience}

The authors analysed and compiled the following comprehensive chart based on the interview responses to state the importance of various parameters in choosing internship.

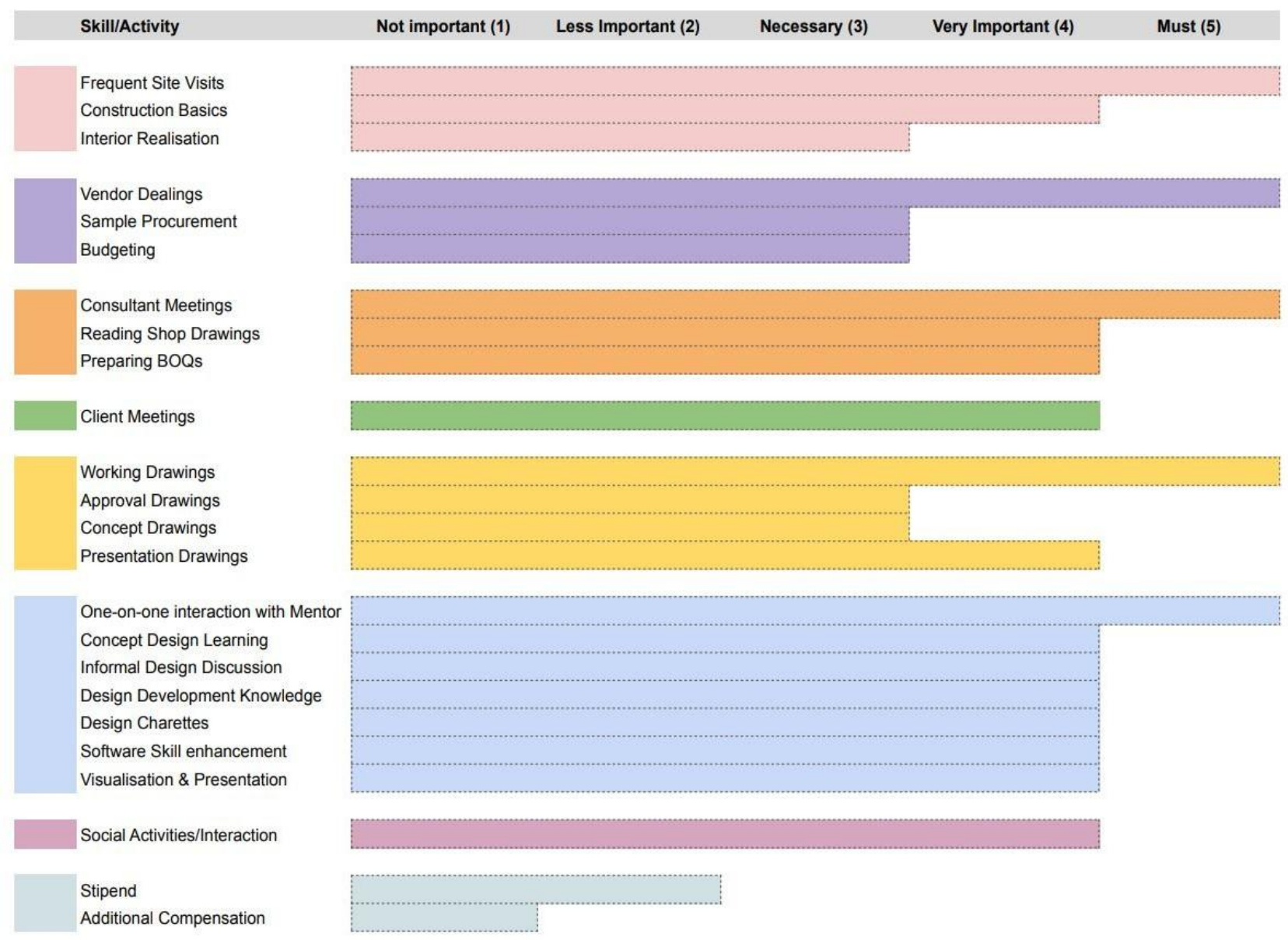

\section{BRIDGING THE GAP/OUT OF BOX SOLUTIONS}

\section{Equalising the varied experience}

Students themselves must speak up, and ensure a fruitful, and rewarding internship by requesting a written profile of the summary of the job and all it entails. They must make sure to communicate with the firm before entering into an internship.

Another solution could be to maintain a combined database of firms and interns could fill in their feedback. Such a database would encourage companies to not exploit interns in the fear of bad feedback and the future interns would have a bank of data to look from. This database would include fields such as number of site visits per week, number and scale of projects handled, variety of work done, scope of learning, degree of communication between peers, mentors, \& work atmosphere.

\section{Solutions to address concerns of Interns}

Interns must communicate with seniors and form review excel sheets, with firms ranked accordingly in terms of preference. This would help them sort issues out and have the best preference for all the firms they decide to apply for. Further, they must speak to previous interns of the office in question about their experience. In conclusion, in a world of exploitation, one must be ready beforehand and have all the information about the subject.

\section{Methods Firms can adopt to realize the true potential of Interns}

Firms can employ the following methods to broaden their portfolio and realize the true potential of interns :

- Architectural walks, trips, talks, etc.

- Weekly sessions to discuss architectural innovations, and breakthroughs.

- Weekly debates, and joint review sessions

- Charettes 
- Model Making

\section{ANALYSIS AND CONCLUSION}

Architecture firms are either buzzing with activity, some new developments and conundrums or they can be stagnant, depending on work flow. Interns can feel a bit lost at first. Also, communication and creating contacts are crucial. Interns should always communicate their needs and shouldn't wait around for others to come and offer support, be proactive, and not be afraid to ask for help and not be scared to request assistance.

Besides receiving the help an intern will need, establishing professional relationships that can prove to be quite fruitful while communicating. Networking and building contacts both in the office and outside of it help build your communication skills and network.

Across the board, it was found that mentors first and foremost expect a willing drive to learn, and basic software skills that can be developed during the internship. Basic professional ethics, such as punctuality, professionalism, and respect for the work environment go without saying. Specific knowledge of detailed construction practices are not required, because firms treat interns at "blank slates", and are willing to teach, if interns are willing to, and show initiative to learn. Often, it is believed that interns do not add much to the firm, as much as they invest in interns. And when it comes to what the interns can add to the firm, it's mostly in terms of software skills, interns often can't add in terms of design and give input on that as they lack experience and knowledge.

\section{The Academic Disconnect}

This research makes it clear that a gap exists between the academic curriculum requirements and the way the professional practice is taught to the interns at any firm. Following are the major concerns or points of disconnect that the research has identified.

- Architectural colleges focus too much on pursuing architectural drawing work on an internship while most students get to do interiors, which is as important to the design process. This causes a rift between the college and students as students are misled to believe that their interior portfolios wouldn't hold through the jury. This is the primary reason for students to experience deviance. Thus, it has concluded that the academic curriculum needs to be more aware of the current professional practices, instead of undermining the importance of learning interiors as architects.

- The other issue that mentors and students feel alike is that the stipulated time for internships is way too less for any student to gain meaningful insights. Most colleges stress on a minimum of 3-4 months of internships, (in a singular semester internship) while the mentors and students argue that a bare minimum of 6 months is required to make the internship truly fruitful.

Thus, students and colleges must work together to give preferable outputs to a firm, and in turn the firm should give to the system by preparing the next generation of responsible architects. An internship, just like any other job, is a back and forth between the give and take of resources. Colleges must maintain educational standards fit to equip students embarking on internships. A healthier learning environment could be fostered, which will let go of the rudimentary academic requirements and would be more conducive to the present trends of professional practice leading to holistic development.

\section{CONCLUDING INFERENCES FROM THE RESEARCH}

Thus, following notable inferences have been made from the research

- The academic disconnect in terms of minimum requirements need to be clarified and extended for better experiences.

- Interior internships should be paid importance from the academic perspective.

- Firms should encourage interns to do more exploration than just presentation work.

- The students should take initiatives and be enthusiastic about finding the right internship experience.

- Internships should be treated as important stepping stones into the profession and not just a means of earning money.

- Seniors interns/employees should be encouraging and helpful in guiding the upcoming batches to seek the best internship opportunities.

- Finally, a student should be well-researched and sure about what to expect from the internship and what firm will be the right choice for them.

\section{REFERENCES}

1. Architecture internships in India 'exploitative' says recent graduate (2019). Dezeen. Available at:https://www.dezeen.com/2019/04/29/unpaid-internships-india-architecture/ (Accessed: 5 November 2020).

2. Elemental ends internships amid growing row over unpaid work in architecture studios(2019a). Dezeen. Available at: https://www.dezeen.com/2019/03/27/elemental-unpaid-internships-row/(Accessed: 5 November 2020). 
3. Elemental ends internships amid growing row over unpaid work in architecture studios(2019b). Dezeen. Available at: https:/www.dezeen.com/2019/03/27/elemental-unpaid-internships-row/ (Accessed: 5 November 2020).

4. Gündeş, S. (2017). An empirical study of internship practices in architectural education: Studentperspectives. MEGARON / Ylldız Technical University, Faculty of Architecture E-Journal.

5. Parishani, N. and Khorooshi, P. (2016). Challenges and Opportunities of Internship Lessons inthe View of Students from Farhangian University Case Study: Colleges of PardisFatemeh Zahraand ShahidRajai in Esfahan. Mediterranean Journal of Social Sciences.

6. Unpaid interns are 'used and abused' by Japanese architects says Cameron Sinclair(no date). Available at: https://www.dezeen.com/2019/12/06/cameron-sinclair-unpaid-interns-abused-japan/ (Accessed: 5 November 2020). 